\title{
Gravitational Model to Predict the Megalopolis Mobility of the Center of Mexico
}

\author{
Juan Bacilio Guerrero Escamilla, Sócrates López Pérez, Yamile Rangel Martínez, Silvia \\ Mendoza Mendoza*
}

*Academic Area of Sociology and Demography, Institute of Social Sciences and Humanities, Autonomous University of the State of Hidalgo. Pachuca City, Hidalgo State,México. Kilometer 4.5, Pachuca / Actopan Road, San Cayetano Neighborhood, P.C. 42084, Phone(51) 771-7172000 ext. 5200 to 5234.

\begin{abstract}
Since 1950, Mexico has presented an accelerated migration process to the country's capital, Mexico City. Here is where new settlements emerged increasing its population, and as a positive consequence, employment improved together with provisions. This growth occurred until the 1980s, when a conurbation happened with some municipalities of the State of Mexico, creating the Metropolitan Area of the Valley of Mexico. In the beginning of the $21^{\text {st }}$ century, new challenges arose with the integration of more metropolitan areas in the states of Mexico (Valley of Toluca), Hidalgo, Morelos, Puebla, Tlaxcala and Queretaro.

This document is the result of two extensive research projects that took place from 2008 to 2016, along with the population institutions of the states that were integrated. The objective was to demonstrate the existence of the Megalopolis and its operation, based on a sociodemographic model to understand its composition and characteristics. However, when limited to demographic variables, it was difficult to analyze its operation. Therefore, the Gravitational Model was designed to establish the great diversity of mobility relationships to account for the functional composition. Thus, the population mobility that commutes daily to the interior of the Megalopolis will be the fundamental factor to explain its operation.
\end{abstract}

Keywords - Mexico Megalopolis, Gravitational model, Population mobility, Commuters model, Metropolitan Areas of Mexico, Urbanization of cities of Mexico.

\section{INTRODUCTION}

In the last fifty years, Mexico has gone through a number of demographic phenomena, including migration processes. These have varied in intensity according to the time period and great diversity in its forms, whether internal intermunicipal, rural-urban, interstate and international. Internal migration is highlighted, since it has been the main way to define the setup of the current territory, the geographical distribution of its population, the definition and composition of its regions, the growth and consolidation of cities, and the current relationship between urban-rural populations.

At the same time, these internal population movements have been determinant factorsfor demographic dynamics, changes in the country's geographical distribution, economic diversification, integration of employment markets, and the population of big citiesthat have become attraction centers of population migration [1].This demographic phenomenon is no longer the movement of the population from the countryside to the city.Now, migration is taking place among various urban centers, reaching high levels in the medium cities, generating mass displacements from the center of the Megalopolis towards a new network of intermediate cities and metropolitan areas of the states surrounding Mexico City as well asthe Municipalities of the State of Mexico [3].

1.1 Integration of Metropolitan Areas in Mexico

In Mexico, the form of settlement defined as Metropolitan Areas (ZM as per its Spanish acronym for "Zona Metropolitana"), is a phenomenon that has been very dynamic,enabling to define population nucleithroughout the country and exceeding the municipal and state limits. These (ZM's) are characterized by being an urban regionthat includes a central nucleus linked to other smaller conglomerates (cities or municipalities); these are intertwined by sharing specific functions, such as industry, services, commerce and culture. This implies the formation of a system in which a central city establishes a network of relations with other cities or municipalities, as well as maintaining a high population density, where the size is related to the group of municipal administrations that are integrated [1].The ZM'swere starting points for the emergence of large spaces of differentiated trading, its own dynamics and resources, the application, design and development of large investment projects in various sectors, 
and its own dominant center. ZM's are linked to peripheries and suburban spaces, with social groups and culture that gives them their own identity. This leads us to conceptualize the megalopolis of Mexico, beyond the simple integration or absorption of small cities, with urban agglomerates, emergence of suburbs, and dormitory cities or satellites.

The ZM with the largest population, majordynamism, economy, mobility and integration of states and municipalities, is the one that has been formed around Mexico City [7].This ZM, under various demographic processes, hasbeen growing at an accelerated rate in the last decades of the last century. Thisleadsto new population dynamics and changes in its various indicators, rates, growth, displacement and migration [2].This urban region is the sum of numerouscities that have been integrated. According to their growth, an increasingly bigger area is being formed, through nuclei that integrate millions of inhabitants, grouped in different cities and with clear relationships of functionality and trade. All of this is forming a megacity, megalopolis or megapolis [4].

\subsection{The Megalopolis}

The term megalopolis is understood as those urban regions that reach or surpass 10 million inhabitants, within the space or territory occupied by several cities [5]. In some cases, it is also defined when they have a population density of at least 2,000 inhabitants per $\mathrm{km}^{2}$. However, the concept does not stop there, the studies carried out during the 1960s on large cities in North America defined Megalopolis in broader terms, since it wasn't limited to population volumes, which led to an integration and functioning of a wider body of cities and urban areas. The term megalopolis was defined as the formation of a set of Metropolitan Areas, whose accelerated urban growth leads to the contact of the area of influence of one another. Thus, the megalopolis usually consists of conurbations of large cities. This concept also includes a Global City that according to its author Saskia Sassen, applies to the cities that have a series of characteristics. These characteristics are the result of globalization and the constant growth of urbanization, including its broader and more comprehensive forms as political, economic and cultural categories.

The most common trend in the formation of a Megalopolis is the urbanization of large territories that have different ZM's that are linked to a single urban system, characterized by maintaining a dynamic interaction between two or more ZM's. The studymentioned previously, points outthatthese areas are wealthy and productive, forming a new urban system which houses the most prosperous andwell-educated groups withaccess to social services [5].

\subsection{Central Mexico area Megalopolis}

One of the first proposals of the central Mexico areamegalopolis was in 1976. Itestablishedthe existence of 12 metropolitan areas [15]within the context described by the UN in 1966, by considering them as the territorial extension that includes the political-administrative unit that contains the central city, and the contiguous politicaladministrative units that have urban characteristics such as workplaces or residences of non-agricultural workers. Also,they maintain a direct, constant and intense socioeconomic interrelationship with the central city and vice versa [3].Later, inan analysis from the 1980s, the Megalopolis was defined as the integration of 26 Metropolitan Areas, which included the 12 ZM's of the previous period [11], and defined the formation of the city in a first stage, in which the population, as well as the economic activity, housing and urban services tend to concentrate in the center of the city. This is followed by a second phase of physical expansion of the city and expansion of its influence radius; suburbanization is generated and new work centers and concentration of services appear within the urban area. If, in this process, the city absorbs one or more political-administrative units, close and external, they will growaround it and with that, a Metropolitan Area will appear [10].

In 1993, new areaswere aggregated to the territory.Jaime Sobrino identified 37 metropolitan areas by pointing to the metropolitan areas with contiguity and integration graphs.At the same time, he integrated a statistic and applied the main components method with the variables of demographic growth rates, urbanization rate, GDP of the municipal manufacturing industry and coverage of drinking water services [14].

Recently, new proposals have been presented under a delimitation, considering the urban character of the municipality and the intermunicipality trips due to commuting.In addition, the demographic dynamics and the economic importance of the municipality are identified in 48 Metropolitan Areas which population represented almost half of the national population in the year 2000 [13].

The National Institute of Statistics Geography and Informatics (INEGI, as per its Spanish acronym), marked 32 Metropolitan Areas integrated by 205 municipalities, consideringthe size of the city and its relation of physical contiguity, and also based on the cartography of the national geostatistic framework and urban AGEB [6]. 
In more recent studies, and following the international urbanization trends, a metropolitan area is considered a central place that remains as a political-administrative unit, containing an urban area with 50 thousand or more inhabitants. However, for any unit to be part of a metropolitan area, it must be in territorial contiguity and maintain certain physical-geographical, socioeconomic and functional integration variables.

In 1995, the National Population Council (CONAPO, as per its Spanish acronym)identified 31 Metropolitan Areas and defined it as a set of two or more municipalities that contained, within its boundaries, a city of 100 thousand or more inhabitants, and whose population and productive activities had urban characteristics.

In 2003, CONAPO identified 42 Metropolitan Areas, integrated by 243 municipalities, pointing to its definition, the size and conurbation (physical union), the functional integration related to the displacement of the employed population between the municipalities of residence and work, as well as criteria on the urban character of the municipalities.

The Secretariat of Social Development (SEDESOL, as per its Spanish acronym), based on the National Urban Development Program 1990-1994, 1995-2000, 2001-2006; specified that a Metropolitan Area was defined as "Those city networks, where the metropolization processes that involve cities of Mexico and the United States of America or cities that have more than a million inhabitants".

\section{THEORETICAL FRAMEWORK AND DEVELOPMENT OF THE GRAVITATIONAL MODEL}

In the report on Urban Poverty and Metropolitan Areas in Mexico presented by the National Council for the Evaluation of the Social Development Policy (CONEVAL, as per its Spanish acronym) in 2013, a metropolitan area was defined as a group of municipalities in a single unit sharing a central city and that are functionally interrelated. This concept was developed in the United States in the early 1920s and refers to a large city where its limits exceed the political-administrative unit of a municipality. This process of metropolization is understood as "the special dynamics generated by the changes made in the production mode that involves the trend association of city networks or urban agglomerations constituting an urban conglomerate with common characteristics: economic, social, functional and productive, which define the flow of goods, people and financial resources".
Within the center of the country'smetropolitan areas, continuous displacements of the population are generated, which are known as commuting. That is to say, it is the travel done by the inhabitants of a metropolitan area from their place of residence to their destination, where the intensities of displacements provide elements to determine the strength that drives the city's growth.

A City is defined as an agglomeration that includes considerable extensions that surpass its limits and that were historically marked by a past political decision. At present, cities in metropolitan areas at the center of the country expand beyond their original administrative area, reaching spaces of other cities, forming a large metropolitan area that exceeds its administration.

In this context, metropolitan areas reach a depletion limit in the proper use of their resources, which causes major problems, such as an inefficient infrastructure with low maintenance, low tax collection, increased insecurity and excess pollution. These problems result in continuous population displacements among the different metropolitan areas, resulting in an economic and social dynamic where mobility is related with a cost-benefit analysis.

Based on the above, the population mobility experienced in the metropolitan areas of the center of the country is the result of the economic and social growth that these regions have developed over time. This element gives rise to the need to measure the magnitude of mobility among the different areas. Therefore, this document has a theoretical basis in the gravitational law, because by its application it will be possible to predict the dynamics of the inhabitants commuting, and with this, measure the degree of specialty, by identifying the benefits and difficulties that each one of them currently present.

The gravitational law (2ndlaw of Issac Newton, 1642-1727) is part of mechanical physics and aims to describe the gravitational interaction between different bodies with mass. Newton demonstrated that the force of gravity has the direction of the line that connects the centers of the stars and the direction corresponds to an attraction [9].

Newton discovered that the force of attraction of two bodies is expressed as follows:

$$
\begin{array}{ll} 
& \text { Where: } \\
& \overrightarrow{\mathrm{F}} \text { is the foce exerted between both } \\
& \text { bodies. } \\
& \mathrm{M} \text { is the mass of attraction of } \\
& \text { object one. } \\
& \mathrm{m} \text { is the mass of attraction of } \\
& \text { object two. } \\
& \mathrm{R} \text { is the distance that exists }
\end{array}
$$


between both objects.

$\mathrm{G}$ is the universal gravitation constant.
Equation (1) means the following:

"The force of gravity between two bodies is proportional to the product of their masses and inversely proportional to

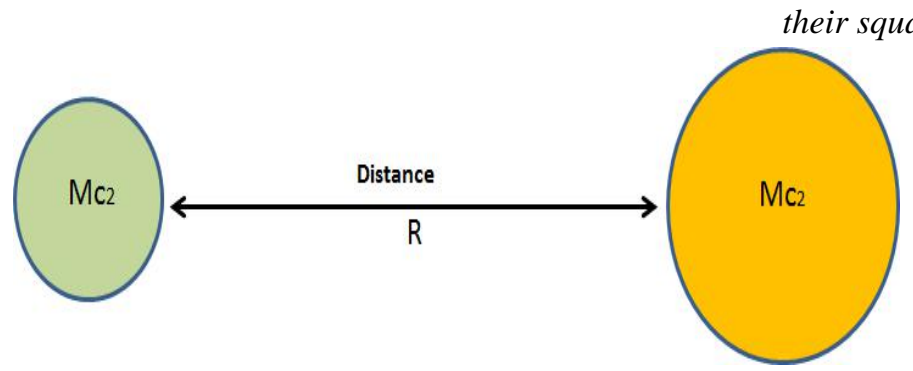

Fig.1: Graph of force of attraction between two bodies.

Source. Own elaboration, México, 2017.

That is, the greater the weight of the masses of both bodies, the greater their attraction, but this will depend on the distance between them, therefore we assume the following [8]:

- The greater weight of the mass between the bodies, the greater force of attraction.

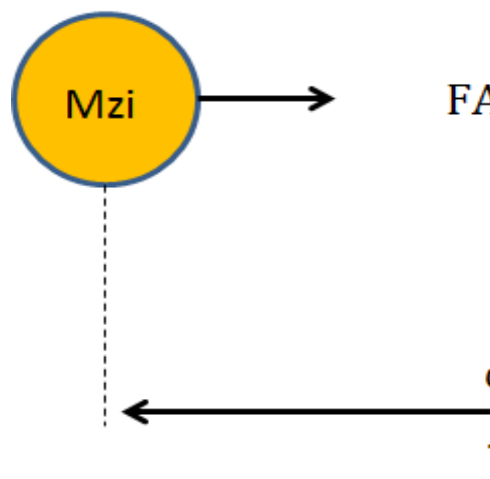

Fig.2: Graph of the force of attraction of two metropolitan areas.
- The smaller the distance between the bodies, the greater force of attraction.

Based on the above, the attraction force of one Metropolitan Area with respect to another will depend on the weight of their masses and inversely proportional to the distances and the time needed to cover those distances (Figure2).

Source. Own elaboration, México, 2017.

That is:

"The force of attraction between two metropolitan areas is proportional to their masses, and inversely proportional to the square of their distance"

Therefore, from the theory of gravitational law, the force of attraction of two Metropolitan Areas is expressed as follows:

$$
\mathrm{FA}_{\mathrm{i}}=\left[\frac{\left(\mathrm{M}_{\mathrm{i}}\right)\left(\mathrm{M}_{\mathrm{j}}\right)}{\left(\mathrm{d}_{\mathrm{i}}\right)^{2}}\right] * 100 ; \quad \mathrm{FA}_{\mathrm{i}} \in \mathcal{R}^{+} ; \mathrm{i} \neq \mathrm{j}
$$

Where:

- $\quad \mathrm{FA}_{\mathrm{i}}$ is the rate of the force of attraction between the $\mathrm{i}$-th metropolitan area and the $\mathrm{j}$-th metropolitan area.
- $\mathrm{Mi}$ is the attraction mass of the i-thmetropolitan area.

- $\quad \mathrm{Mj}$ is the attraction mass of the $\mathrm{j}$-th metropolitan area.

- di is the distance between the i-th metropolitan area and the $\mathrm{j}$-th metropolitan area $(\mathrm{Km})$.

The dynamic mobility rate (commuting)of the i-th Metropolitan Area in relationto the others is expressed as follows:

$$
\begin{gathered}
\mathrm{FA}_{\mathrm{Ti}}=\int_{\mathrm{b}}^{\mathrm{a}} \frac{\mathrm{FA}}{10} \mathrm{dPA} \sim \sqrt[10]{\prod_{i=1}^{10} \mathrm{FA}_{\mathrm{i}} ; \mathrm{FA}_{\mathrm{i}}} \\
\in \mathcal{R}^{+} \quad(3)
\end{gathered}
$$

Its interpretation is as follows: 
- $\quad$ The mobility rate between the metropolitan areas is identified as the degree of population displacement, which will depend on their confidence intervals.

$$
\text { Lower limit }(\mathrm{LI})\left\{\overline{\mathrm{X}}-(1.96)\left(\frac{\sigma}{\sqrt{\mathrm{n}}}\right)<\mu<\right.
$$

Where:

- $\quad$ IfFA $_{\mathrm{Ti}}: \mathrm{FA}_{\mathrm{i}} \sim \mu$, there is moderate mobility.

- IfFA $_{\mathrm{Ti}}: \mathrm{FA}_{\mathrm{i}}<\mu$, there is low mobility.

- $\quad$ IfFA $_{\mathrm{Ti}}: \mathrm{FA}_{\mathrm{i}}>\mu$, there is high mobility.

Just as the force, the attraction mass of a metropolitan area is illustrated through its confidence intervals.

- $\quad$ IfM $_{\mathrm{i}}: \mathrm{M}_{\mathrm{j}} \sim \mu$, there is a moderate attraction mass.

- $\quad$ IfM $_{\mathrm{i}}: \mathrm{M}_{\mathrm{j}}<\mu$, there is a low attraction mass.

- $\quad$ IfM $_{\mathrm{i}}: \mathrm{M}_{\mathrm{j}}<\mu$, there is a high attraction mass.

- The force of attraction between metropolitan areas is interpreted as population mobility.

- The mass of attraction is interpreted as the socialeconomic benefit that a metropolitan area produces when living there.

Through the building of this model, it will be possible to know the dynamics of population mobility, which will be determined by the people's needs required to sustain their livelihood within their economic and social environment.

Predicting and identifying the dynamics of mobility as well as the specialization of metropolitan areas involves the development of a deterministic model (mathematical model).Therefore, building an abstract and simplified reality of the analyzed phenomenon, results in an empirical study where the results obtained can help to make decisions [12]. The development of the deterministic model of this research paper is presented in four phases[11]:

1- Mathematical formulation: this first phase consists of transcribing into mathematical language the mobility dynamic of the Metropolitan Areas.

2- Resolution: in this second stage, all the proper mathematical operations are executed, with the purpose of obtaining logical and adequate results regarding the mobility dynamic of the metropolitan areas.

3- Interpretation: in this stage, the results obtained in the model must be interpreted though the use of graphs of the mobility phenomenon inthe metropolitan areas.
4- Predictions: in this last stage and through the interpretation of the model's results, the benefits and limitations of each one of the metropolitan areas must be identified, and with that, the specialization degree.

Based on the above, the study's target population is the commuters of the eleven metropolitan areas of the center of the country. This is because in 2008 they concentrated more than 40 percent of the economic activity of the country. In addition, they grouped more than 34.5 percent of the total population.

Predicting and identifying the mobility dynamics of commuters in the metropolitan areas involves the following assumptions:

- The population of the metropolitan areas is in constant mobility.

- This mobility is derived from a cost-benefit analysis.

\section{METHODOLOGY OF THE GRAVITATIONAL MODEL}

Based on the above, the mathematical formulation of the attraction force between two Metropolitan Areas is determined by the following algebraic expression:

$$
\mathrm{FA}_{\mathrm{i}}=\left[\frac{\left(\mathrm{M}_{\mathrm{i}}\right)\left(\mathrm{M}_{\mathrm{j}}\right)}{\left(\mathrm{d}_{\mathrm{i}}\right)^{2}}\right] * 100 ; \quad \mathrm{FA}_{\mathrm{i}} \in \mathcal{R}^{+} ; \mathrm{i} \neq \mathrm{j}
$$

So that:

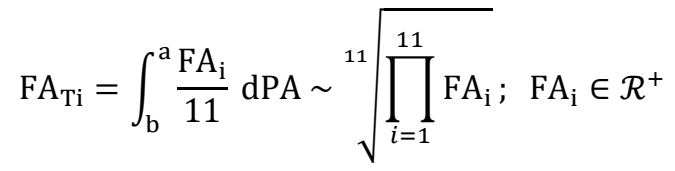

In order to evaluate the mobility or commuting rate amongMetropolitan Areas, its mathematical resolution is to calculate the expected value of the attraction mass of the itch metropolitan area, which is obtained as follows:

$\mathrm{E}\left[\mathrm{M}_{\mathrm{i}}\right]$

$=\sqrt[10]{\left(\overline{\mathrm{X}}_{1}\right)\left(\overline{\mathrm{X}}_{2}\right)\left(\overline{\mathrm{X}}_{3}\right)\left(\overline{\mathrm{X}}_{4}\right)\left(\overline{\mathrm{X}}_{5}\right)\left(\overline{\mathrm{X}}_{6}\right)\left(\overline{\mathrm{X}}_{7}\right)\left(\overline{\mathrm{X}}_{8}\right)\left(\overline{\mathrm{X}}_{9}\right)\left(\overline{\mathrm{X}}_{10}\right)}$

So that:

Where:

$$
\mathrm{E}\left[\mathrm{M}_{\mathrm{i}}\right] \in \mathcal{R}^{+} \rightarrow 0<\mathrm{E}\left[\mathrm{M}_{\mathrm{i}}\right] \leq 100
$$

- $\bar{X}_{1}$ is the attraction mass related toeducation

- $\bar{X}_{2}$ is the attraction mass related to health

- $\bar{X}_{3}$ is the attraction mass related to energy

- $\quad \bar{X}_{4}$ is the attraction mass related to housing

- $\bar{X}_{5}$ is the attraction mass related to non-poverty

- $\bar{X}_{6}$ is the attraction mass related to water

- $\bar{X}_{7}$ is the attraction mass related to public security 
- $\overline{\mathrm{X}}_{8}$ is the attraction mass related to transportation and infrastructure

- $\bar{X}_{9}$ is the attraction mass related to noncontamination

- $\quad \bar{X}_{10}$ is the attraction mass related toemployment The expected value of any $\overline{\mathrm{X}}_{\mathrm{i}}$ is obtained by standardizing the information through logarithms.

The estimation and interpretation of the results of the present model are structured from two aspects:

1- The prediction of the mobility dynamics of commuters of metropolitan areas, taking each one of their attraction massesas a reference.
2- The measurement and identification of the specialty of each one of the metropolitan areas, derived fromthe mobility dynamics of commuters.

By reading these results, it will be possible to make projections onthe socio-economic trend that each one of the metropolitan areas must follow, which will provide the necessary elements to propose a megalopolitan management, with the purpose of obtaining a better distribution of the economic resources that each one of them generates.

Themobility dynamics of the metropolitan areas will be interpreted as the commuting degree that the inhabitants of each area are willing to experience.
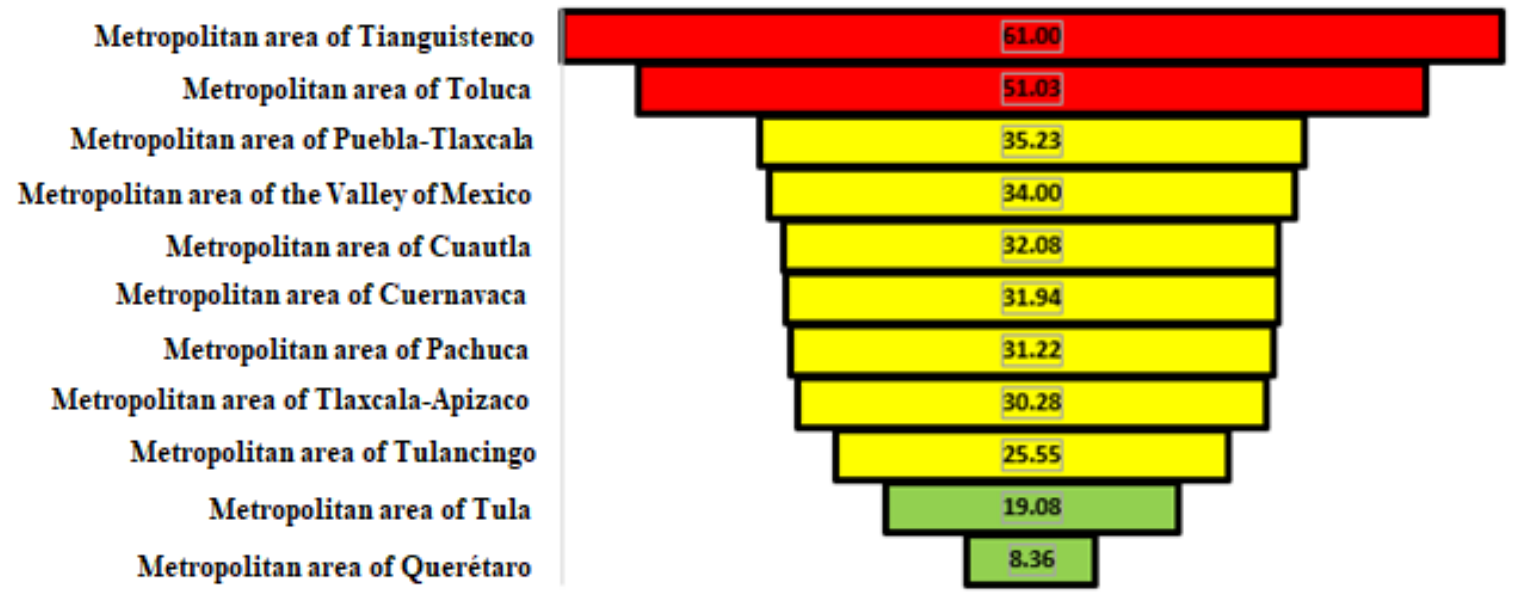

Fig.3: Mobility degree per Metropolitan Area.

Source. Own elaboration, México, 2017.

Based on figure4, it can be seen that the Tianguistenco and Toluca areas experience a high degree of mobility (61 and 51 units), when compared to the others. On the other hand, Tula and Queretaro are the ones with less mobility, while the other areas have a homogeneous behavior.

Example: the mobility rate of all the Metropolitan Areas is 29.50 units:

$\mathrm{FA}_{\mathrm{Ti}}=\sqrt[11]{\prod_{i=1}^{11} \mathrm{FA}_{\mathrm{i}}}$

$=\sqrt[11]{(61)(51.03)(35.53)(34)(32.08)(31.94)(31.22)(30.28)(25.55)(19.08)(8.36)}$

Therefore:

$$
\mathrm{FA}_{\mathrm{Ti}}=\sqrt[11]{\prod_{\mathrm{i}=1}^{11} \mathrm{FA}_{\mathrm{i}}}=29.50 \text { units }
$$

Where:
- FAi is the expected value of the attraction in the i-th attraction mass, which is obtained from the following algebraic expression:

$$
\mathrm{FA}_{\mathrm{i}}=\left[\frac{\left(\mathrm{M}_{\mathrm{i}}\right)\left(\mathrm{M}_{\mathrm{j}}\right)}{\left(\mathrm{d}_{\mathrm{i}}\right)^{2}}\right] * 100 ; \quad \mathrm{FA}_{\mathrm{i}} \in \mathcal{R}^{+} ; \mathrm{i} \neq \mathrm{j}
$$

The masses drivingthe mobility of all the metropolitan areas are the following (figure 5):

Housing. As a social entity, it is the place where the family settles, lives, grows and thrives. Therefore, it is the economic and social development of the individual [3]. 


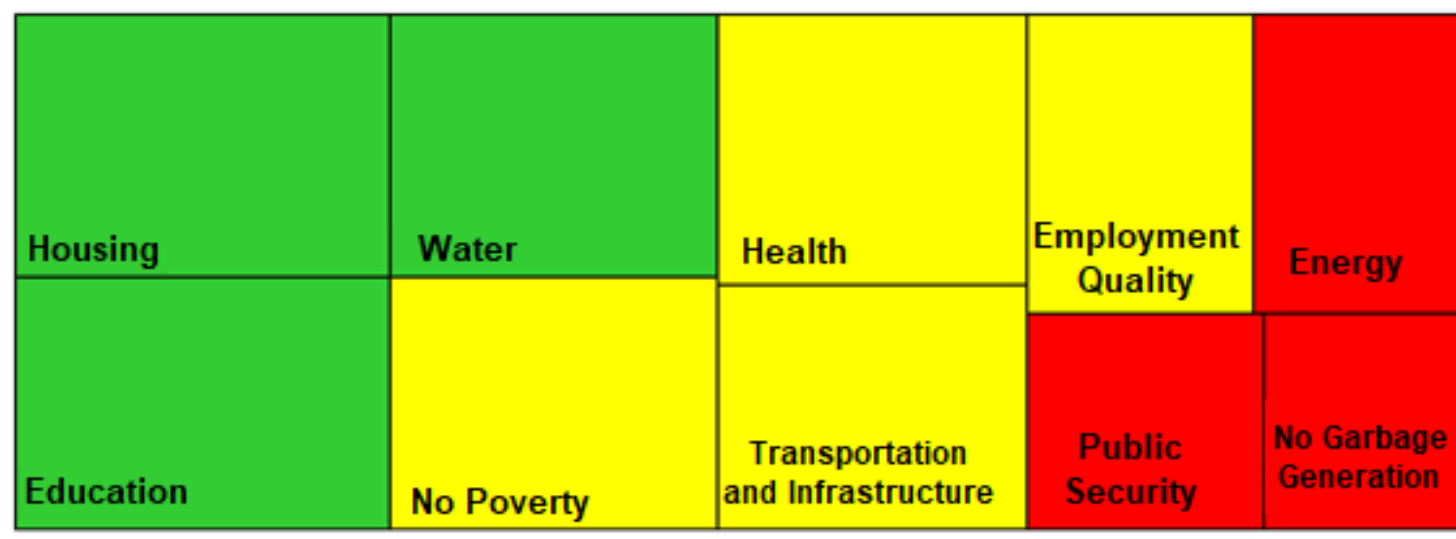

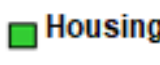

$\square$ No Poverty

Employment Quality $\square$ Education

$\square$ Health

$\square_{\text {Energy }}$

\section{Water}

Transportation and Infrastructure

Public Security

$\square$ No Garbage Generation

Fig.4: Rank of majorinfluence masses in the commuting amongthe metropolitan areas inthe center of the country. Source. Own elaboration, México, 2017.

- Education:The tool must transmit knowledge, values, customs, behaviors, attitudes and course of actions that the human being must acquire and use throughout their life.

- Water: it is the most important non-renewable resource for the survival of any living being. This resource gave rise to life and it sustains it; it is a factor that regulates the planet's weather.It creates and allows the existence of ecosystems and mankind.

Meanwhile, health, transportation, infrastructure, employment quality, and the fight against poverty generate a moderate mobility, probably due to the following factor: the gap between these attraction masses of each metropolitan area is not very wide.This is presumably because of the living costs in each one of them. Most likely, the Valley of Mexico offers better quality jobs than any other Metropolitan Area, however the costs of livingthere is more expensive than the others.Therefore, a person would have to make a cost-benefit analysis on employment.

On the other hand, in spite of the increase of the environmental and insecurity issues throughout the country, they are notstill elements that strongly detonate population mobility amongthe metropolitan areas.

Based on the above and according to figure 6, the metropolitan area that generates more attraction force is Queretaro, due to four factors (figure 6): highly qualified jobs, low poverty rates, efficiency in energy supply, transportation and infrastructure. 


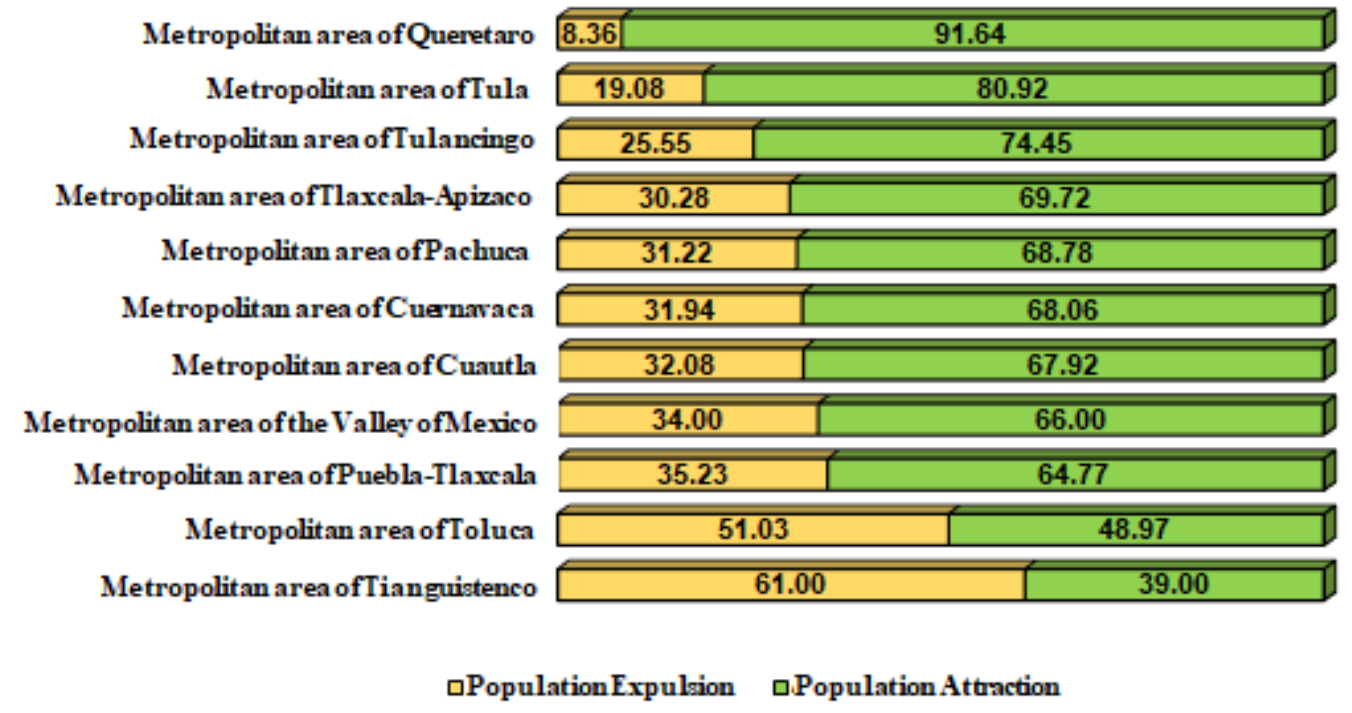

Fig.5: Expulsion and attraction per Metropolitan area.

Source. Own elaboration, México, 2017.

In the example, the mobility rate of all the Metropolitan Areas was 29.50 units, therefore, the attraction force between them would be70.50 units

Therefore:

$$
\begin{gathered}
\mathrm{FA}_{\mathrm{Ti}}=\sqrt[11]{\prod_{\mathrm{i}=1}^{11} \mathrm{FA}_{\mathrm{i}}}=29.50 \text { units } \rightarrow \mathrm{FA}_{\mathrm{Tj}}=100-\mathrm{FA}_{\mathrm{Ti}} \\
=100-29.50=70.50 \text { units }
\end{gathered}
$$

In addition, education, health, water, public security and garbage collection behave similarly to the other metropolitan areas (except for Puebla-Tlaxcala and the Valley of Mexico, because in education and health they are above Queretaro). Their main limitation is house acquisition due to rising home prices as a result of the cost of living increment in the area.

The second metropolitan area with greater attraction is Tula due to two factors:
- It ranks 3rdin offering the best jobs because the Miguel Hidalgo refinery and the Fortaleza cement factory are located within its territory. Also, it has one of the most important archeological areas in the state of Hidalgo.

- Tula presents a moderate attraction force in education, health, energy, housing, water supply, public security, transportation, infrastructure, and fight against poverty. However, currently it has major issues with garbage collection which contributes to the high pollution rates. Most of the pollution comes from the Miguel Hidalgo refinery and the Fortaleza cement factory. 


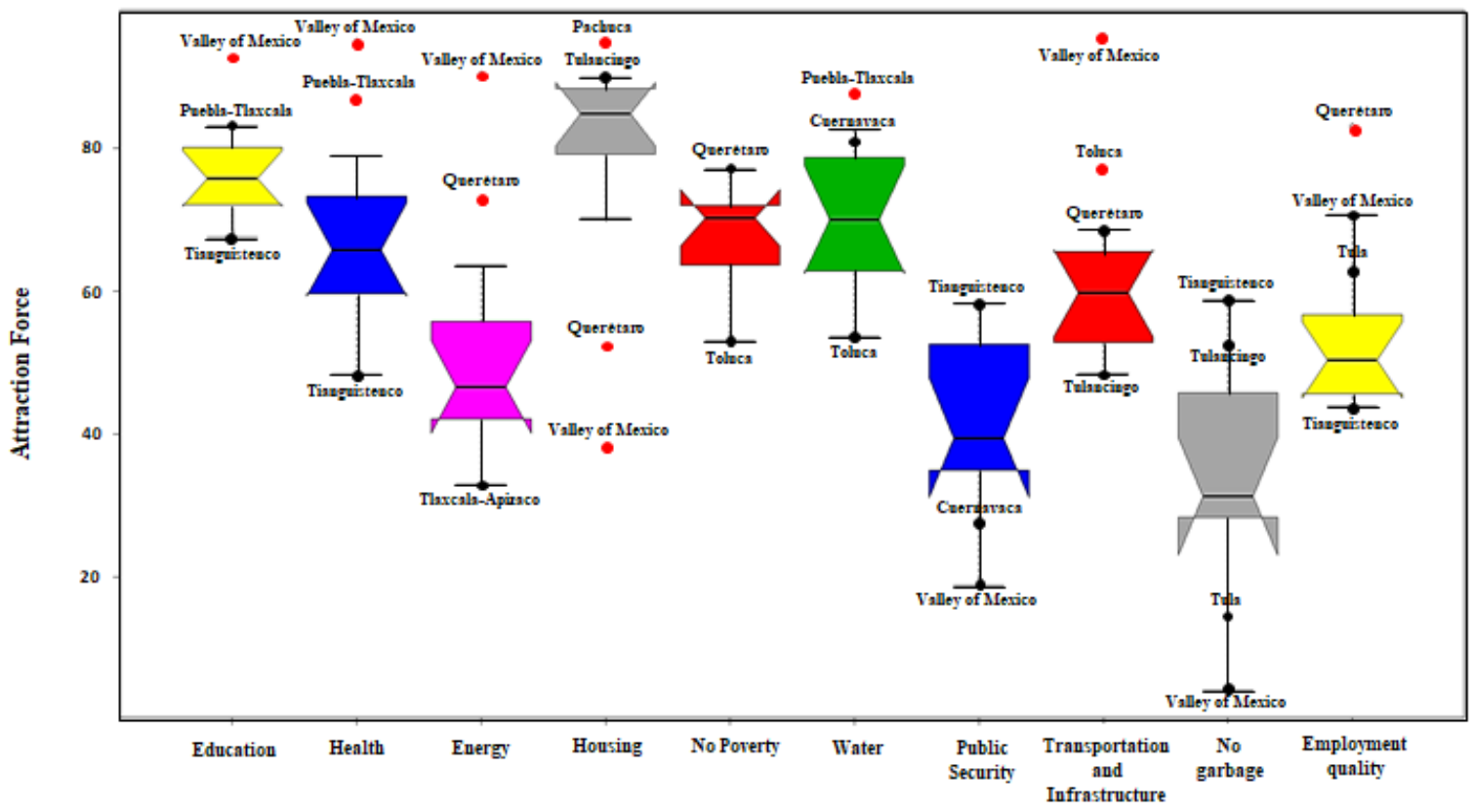

Fig.6: Boxplot of attraction force per Metropolitan area by mass of attraction.

Source. Own elaboration, México, 2017.

The metropolitan area of Tulancingo is in third place in attraction force due to three factors:

- Housing acquisition cost is low; therefore, it is the largest mass of attraction within the Area.

- Its garbage collection system is efficient.

- It has a homogeneous behavior compared to the other areas in education, health, employment, public transportation and infrastructure, public security, water, energy, and fight against poverty.

The metropolitan area of Tlaxcala-Apizaco presents a force of attraction of 69.72 units. This is because health, education, employment, public transportation and infrastructure, public security, water and fight against poverty present a similar behavior to other areas, except for Puebla-Tlaxcala, Valley of Mexico and Queretaro that are significantly superior in education, health, employment, public transportation and infrastructure. Therefore, the mobility experienced by their inhabitants will be towards those areas. Its main weakness is energy supply.

For the metropolitan area of Pachuca, its attraction force is of 68.78 units due to the following:

- Its greatest strength is housing, as acquisition costs are much lower than all other areas.

- It has a moderate behavior in education, health, energy, transportation, infrastructure, garbage collection, employment quality, and fight against poverty. However, in education, health, energy and fight against poverty it is surpassed by the Valley of Mexico, Puebla-Tlaxcala and Queretaro.

- In public security, it is vastly superior to Cuernavaca and the Valley of Mexico.

- Its transportation and infrastructure is more efficient than Tulancingo's, but inferior to the Valley of Mexico, Toluca and Queretaro.

- In garbage collection, it is more efficient than Tula and the Valley of Mexico, however, it is surpassed by Tianguistenco and Tulancingo.

- Its employment quality is inferior to Queretaro, Valley of Mexico and Tula.

The Metropolitan Area of Cuernavaca, has an attraction force of 68.06 unitsdue to the following:

- Its main strength is water supply, ranked just below the metropolitan area of Puebla (top position)

- It has moderate behavior in education, health, energy, housing, transportation and infrastructure, garbage collection, and employment quality.

- Regarding education and health, it is surpassed by the Valley of Mexico and Puebla-Tlaxcala.

- In the energy supply, it is inferior to the Valley of Mexico and Queretaro.

- Its housing cost is moderate, however, it is surpassed by Pachuca and Tulancingo. 
- Transportation and infrastructure have better quality in the Valley of Mexico, Toluca and Queretaro.

- Its garbage collection system is less efficient than Tianguistenco and Tulancingo.

- Their employment quality is inferior to Queretaro, Valley of Mexico and Tula.

For the metropolitan area of Cuautla, its force of attraction is 67.92 units and this behavior is due to the fact that its attraction masses exhibit a moderate behavior.However, the mobility of its population (32.08 units) is due to the following factors:

- In education, health and energy it is surpassed by the Valley of Mexico, Puebla-Toluca andQueretaro.

- The cost of housing is above Pachuca and Tulancingo, however, it is inferior to Queretaroand the Valley of Mexico.

- In the fight against poverty, it is more efficient than Toluca, but inferior to Queretaro.

- Its water supply is more efficient than that of Toluca, but less efficient than that of PueblaTlaxcala and Cuernavaca.

- In public security it is above Cuernavaca and the Valley of Mexico, and below Tianguistenco.

- Public transportation and infrastructure is more efficient than that of Tulancingo, however, it is below Queretaro, the Valley of Mexico and Toluca.

- Its garbage collection system is better than the Valley of Mexico and Tula, but inferior to Tianguistenco and Tulancingo.

- The employment quality does not compare to the Valley of Mexico, Queretaro and Tula, however, it is comparable with the other metropolitan areas, except for Tianguistenco.

The metropolitan area of the Valley of Mexico has an attraction force of 66 units due to the high indicators in education, health, energy, transportation and infrastructure, and employment quality but inferior to Queretaro's. Its main weaknesses are the high cost of housing, the public security system and the way garbage is collected. These indicators are also supported by data provided by INEGI in 2015. This showed that the activity with the highest prevalence in the Valley of Mexico is the tertiary sector (education, health and finance, among others), concentrating 66.27 percent of all activities.

For the metropolitan area of Puebla-Tlaxcala its attraction force is 64.77 units as a consequence of the great benefits it offers in education, health and water supply (the Valley of Mexico is the only Area that surpasses it in education and health).Its other attraction masses present a moderate behavior, however, there are some areas that surpass it:

- In energy and housing by the Valley of Mexico, Pachuca and Tulancingo.

- $\quad$ In the fight against poverty by Queretaro.

- In public security by Tianquistenco but it is widely superior than Cuernavaca and the Valley of Mexico.

- In transportation and infrastructure, the Valley of Mexico, Toluca andQueretaroare superior.

- In garbage collection by Tianguistenco and Tulancingo.

- Employment quality by the Valley of Mexico, Queretaroand Tula.

The metropolitan areas with lower attraction force are Toluca and Tianguistenco (48.97 and 39.00 units):

- Toluca's attraction force is determined by the following:

- Its strength in public transportation and infrastructure.

- Its limitations in education, health, water supply, energy, and employment quality.

- In public security and garbage collection it is moderate, however, it is inferior to Tianguistenco and Tulancingo.

- The force of attraction of Tianguistenco is determined by:

- Its strength in public security and garbage collection.

- Its weaknesses in education, health and quality of employment.

- It shows a moderate behavior in public transportation, infrastructure, water, energy and housing

Based on the analysis of the results of all metropolitan areas, the prediction of this model focuses on the specializationof each area (Table1):

- The Valley of Mexico specializes in education, health, transportation, infrastructure and quality employment. However, it presents major problems in house acquisition and public security.

- Queretaro specializes in the highest paid jobs among all the Metropolitan Areas. Also, a high specialization in efficiency of transportation and 
infrastructure, energy supply, and the fight against poverty.

- Tula specializes in creating well-paid jobs, as a result of the electric and cement industries, as well as the tourism in its archaeological area.

- Pachuca specializes mainly in housing due to its low acquisition cost. Just like Pachuca and Tulancingo specialize in housing.

- Tlaxcala-Apizaco has a moderate specialization, since the majority of its attraction masses have an impartial behavior, except for energy supply.

- Puebla-Tlaxcala specializes in education, health and water.

- Cuautla has a moderate specializationin all its attraction masses.
- Cuernavaca specializes in water supply, however, it faces major insecurity problems.

- Toluca specilizes in public transportation and infrastructure, however, its weakness is the fight against poverty and water supply.

- Tianguistenco specializes in garbage collection and public safety, however, it has too many limitations in education, health and employment quality.

As it can be seen, building and developing a gravitational model based onthe mobility of metropolitan areas gives us the necessary elements to affirm where each one of them is economically heading, and with that, making decisions on how to manage and guidethe central area of the country.

Table.1: Specialization of each Metropolitan Area.

\begin{tabular}{|c|c|c|c|c|c|c|c|c|c|c|}
\hline $\begin{array}{l}\text { METROPOLIT } \\
\text { ANAREA }\end{array}$ & Education & $\begin{array}{c}\text { Healt } \\
h\end{array}$ & $\begin{array}{c}\text { Energ } \\
y\end{array}$ & Housing & $\begin{array}{l}\text { Well- } \\
\text { being }\end{array}$ & Water & $\begin{array}{c}\text { Public } \\
\text { Security }\end{array}$ & $\begin{array}{l}\text { Transportati } \\
\text { on } \\
\text { Infrastructur } \\
\text { e }\end{array}$ & $\begin{array}{c}\text { Garbage } \\
\text { management }\end{array}$ & $\begin{array}{c}\text { Employmen } \\
\text { t quality }\end{array}$ \\
\hline \multicolumn{11}{|l|}{ Valley of Mexico } \\
\hline \multicolumn{11}{|l|}{ Queretaro } \\
\hline \multicolumn{11}{|l|}{ Tula } \\
\hline \multicolumn{11}{|l|}{ Pachuca } \\
\hline \multicolumn{11}{|l|}{ Tulancingo } \\
\hline \multicolumn{11}{|l|}{$\begin{array}{l}\text { Tlaxcala - } \\
\text { Apizaco }\end{array}$} \\
\hline \multicolumn{11}{|l|}{ Puebla - Tlaxcala } \\
\hline \multicolumn{11}{|l|}{ Cuautla } \\
\hline \multicolumn{11}{|l|}{ Cuernavaca } \\
\hline \multicolumn{11}{|l|}{ Toluca } \\
\hline \multicolumn{11}{|l|}{ Tianguistengo } \\
\hline & & $\begin{array}{l}\text { High } \\
\text { Speciali }\end{array}$ & tion & & $\begin{array}{l}\text { Moderat } \\
\text { Speciali }\end{array}$ & & & Low Special & tion & \\
\hline
\end{tabular}

Source. Own elaboration, México, 2017.

\section{CONCLUSION}

Through the application of the gravitational model, it was observed that the mobility of all the metropolitan areas in the center of the country is 29.50 units, that is to say, 30 of every 100 inhabitants commute. Specifically, the main drivers are housing, education and water. In addition, its attraction force is 70.50 (71 of every 100 inhabitants have the intention of moving within the center of the country).

The metropolitan area of Queretaro is the one that experiences less population mobility. Moreover, it is the one that generates the greatest attraction force compared to the others, since it offers the best paying jobs in the center of the country. This causesa reduction on their poverty 
indicators. In addition, they have built a solid infrastructure resulting in awider distribution of their wealth. Regarding the population mobility, the metropolitan area of Tianguistenco presents the greatest population mobility and the lowest attraction force, because it has limitations in education, health and employment quality. Its main virtues are public security and garbage collection.

Based on the most influential masses in commuting (housing, education and water), the following could be identified: the metropolitan areas of the Valley of Mexico and of Puebla-Tlaxcala are the ones that offer better education centers, since both have higher education institutions (UNAM, IPN, CIDE, COLMEX, UDLA, BUAP, and UPAEP, among others).In health, just as in education, both areas are the most prominent in the center of the country, since they have important medical centers (Hospital Angeles, Hospital la Raza, Asociación Nacional de Hospitales Privados, Hospital Universitario BUAP, Hospital Puebla, and Sociedad de Beneficencia Española, among others).In water, the model predicted that the metropolitan areas of Puebla - Tlaxcala and Cuernavaca present better efficiency in the water supply. This stresses the importance of optimizing the water consumption and reducing the contamination throughout the socio-economic activities.

Other relevant results from the present model are the security problems that are collectively presented in the metropolitan areas, and to a greater extent in the Valley of Mexico and Cuernavaca. This phenomenon most likely stems from the lack of institutional, political and social agreements related to the functions of the different public powers, because in their absence, there is no link between the public security system and citizens. Therefore, a system is formed where corruption and impunity prevail.

In addition, the employment quality in most of the metropolitan areas is low except for the Valley of Mexico and Queretaro. This behavior is due to the low economic activity, as the result of the low labor productivity. In other words, there is not enough skilled labor, therefore, wages are low. As a consequence, there is little private investment.

\section{REFERENCES}

[1] CONAPO; SEDESOL; INEGI. (2012), Delimitation of Metropolitan Areas of Mexico 2010. National Population Council (CONAPO), Ministry of Social Development (SEDESOL), National Institute of Statistics and Geography (INEGI), Mexico.

[2] CORONA, Reina, \& Luque, Rodolfo. (1992), "Recent Changes in Migration Patterns to the Metropolitan
Area of Mexico City (ZMCM)", Demographic and Urban Studies, vol. 7, no. 2-3, Mexico.

[3] FLORES, Sergio. (2002), "Urban planning and sustainable regional development in the metropolitan area of Puebla-Tlaxcala" in Delgadillo, Javier, Iracheta, Alfonso, Current regional research in Central Mexico, CRIM, UNAM, Mexico, pp. 195-220.

[4] FORSTALL, Richard. (2004), Which Are The Largest? Why Published Populations For Major World Urban Areas Vary So Greatly, Consultant, Richard P. Greene, Northern Illinois University, James B. Pick, University of Redlands, United Kingdom.

[5] GOTTMANN, Jean. (1961), Megalopolis: The Urbanized Northeastern Seaboard of the United States. Editor Literary Licensing ISBN 1258423251, 9781258423254

[6] INEGI. (2002), Statistical Notebooks of the Metropolitan Area of Mexico City. Edition 2002. National Institute of Statistics and Geography (INEGI), Mexico.

[7] LOPEZ, Socrates. (2009), Sociodemographic diagnosis of the megalopolis of the center of the country. Autonomous University of the State of Hidalgo, Mexico, pp. 200.

[8] MARTÍN, I. (2004). General Physics. Spain: University of Valladolid.

[9] MEDINA, A. and Ovejero, J. (2011). Newton's laws and their applications. Spain: University of Salamanca.

[10] NEGRETE, María, \& Salazar, Héctor. (1986). "Metropolitan areas in Mexico, 1980", in Estudios Demográficos y Urbanos, vol. 1, no. 1, The College of Mexico, Mexico.

[11] RÍOS, S. (1995). Modeling Spain: Editorial alliance.

[12] RODRÍGUEZ, J. (2010). Mathematical models. Spain: Open University of Catalonia.

[13] SOBRINO Jaime, (1993), "Government and metropolitan and regional administration", National Institute of Public Administration, A. C., Mexico.

[14] SOBRINO Jaime, (2003), "Delimitation of the metropolitan areas of Mexico in 2000", in the National Population Council (coord.), The delimitation of zones, metropolitan, Mexico, CONAPO, SEDESOL, INEGI, Institute of Geography-UNAM, Mexico, pp. 121-151.

[15] UNIKEL, Luis. (1976), Urban development in Mexico, diagnosis and future implications. The College of Mexico, Mexico, pp. 116 